This item was submitted to Loughborough's Research Repository by the author.

Items in Figshare are protected by copyright, with all rights reserved, unless otherwise indicated.

\title{
Additive manufacturing of physical assets by using ceramic multicomponent extra-terrestrial materials
}

PLEASE CITE THE PUBLISHED VERSION

http://dx.doi.org/10.1016/j.addma.2016.02.002

PUBLISHER

(C) Elsevier

VERSION

AM (Accepted Manuscript)

\section{PUBLISHER STATEMENT}

This work is made available according to the conditions of the Creative Commons Attribution-NonCommercialNoDerivatives 4.0 International (CC BY-NC-ND 4.0) licence. Full details of this licence are available at: https://creativecommons.org/licenses/by-nc-nd/4.0/

\section{LICENCE}

CC BY-NC-ND 4.0

\section{REPOSITORY RECORD}

Goulas, Athanasios, Russell A. Harris, and Ross J. Friel. 2019. "Additive Manufacturing of Physical Assets by Using Ceramic Multicomponent Extra-terrestrial Materials”. figshare. https://hdl.handle.net/2134/20516. 


\section{Accepted Manuscript}

Title: ADDITIVE MANUFACTURING OF PHYSICAL ASSETS BY USING CERAMIC MULTICOMPONENT EXTRA-TERRESTRIAL MATERIALS

Author: Athanasios Goulas Russell A. Harris Ross J. Friel

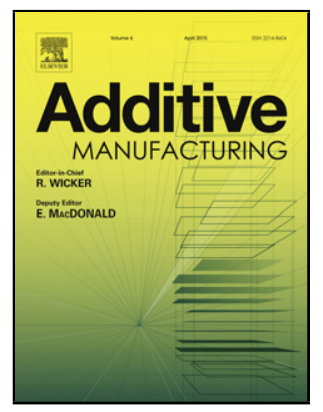

PII:

S2214-8604(16)30032-X

DOI: http://dx.doi.org/doi:10.1016/j.addma.2016.02.002

Reference: ADDMA 67

To appear in:

Received date: $\quad 10-8-2015$

Revised date: $\quad$ 7-2-2016

Accepted date: $\quad 8-2-2016$

Please cite this article as: \{http://dx.doi.org/

This is a PDF file of an unedited manuscript that has been accepted for publication. As a service to our customers we are providing this early version of the manuscript. The manuscript will undergo copyediting, typesetting, and review of the resulting proof before it is published in its final form. Please note that during the production process errors may be discovered which could affect the content, and all legal disclaimers that apply to the journal pertain. 


\section{ADDITIVE MANUFACTURING OF PHYSICAL ASSETS BY USING CERAMIC MULTICOMPONENT EXTRA-TERRESTRIAL MATERIALS}

Athanasios Goulas ${ }^{1}$, Russell A. Harris ${ }^{1}$, Ross J. Friel ${ }^{1}$,

${ }^{1}$ Wolfson School of Mechanical \& Manufacturing Engineering,

Loughborough University, Loughborough, Leicestershire, LE11 3TU, United Kingdom 


\section{ABSTRACT}

Powder Bed Fusion (PBF) is a range of advanced manufacturing technologies that can fabricate three-dimensional assets directly from CAD data, on a successive layer-by-layer strategy by using thermal energy, typically from a laser source, to irradiate and fuse particles within a powder bed.

The aim of this paper was to investigate the application of this advanced manufacturing technique to process ceramic multicomponent materials into 3D layered structures. The materials used matched those found on the Lunar and Martian surfaces. The indigenous extra-terrestrial Lunar and Martian materials could potentially be used for manufacturing physical assets onsite (i.e. off-world) on future planetary exploration missions and could cover a range of potential applications including: infrastructure, radiation shielding, thermal storage, etc.

Two different simulants of the mineralogical and basic properties of Lunar and Martian indigenous materials were used for the purpose of this study and processed with commercially available laser additive manufacturing equipment. The results of the laser processing were investigated and quantified through mechanical hardness testing, optical and scanning electron microscopy, $x$-ray fluorescence spectroscopy, thermo-gravimetric analysis, spectrometry, and finally $\mathrm{x}$-ray diffraction.

The research resulted in the identification of a range of process parameters that resulted in the successful manufacture of three-dimensional components from Lunar and Martian ceramic multicomponent simulant materials. The feasibility of using thermal based additive manufacturing with multi-component ceramic materials has therefore been established, which represents a potential solution to off-world bulk structure manufacture for future human space exploration.

Keywords: Space Additive Manufacturing, Space 3d Printing, On Site Resource Utilisation, Mars, Moon 


\section{1 - INTRODUCTION}

Mankind has always envisioned conquering space, "the final frontier" as acclaimed by many science fiction novelists and aspiring scientists. Setting the first human in orbit around Earth was only the beginning (1); a few years later a number of manned and unmanned missions had managed to establish human presence on the moon (2), land robotic missions on planet Mars $(3,4)$ and, very recently, visit an actual comet (67P/Churyumov-Gerasimenko) (5). Although a reduction in manned space missions has been the status quo for the past few decades, it now seems that a new age of space exploration is at the doorstep and major space agencies have announced their plans towards realising this new age by gradually re-advancing from Low Earth Orbit (LEO) missions to the Moon and later onto the planet Mars $(6,7)$.

The benefits of establishing a human outpost off-world (i.e. the Moon) are multifold, with the most valuable asset being the gathering of data and attaining knowledge on off-world survival with the chance to develop strategies to retain human presence in space and reach even further to other planetary bodies (i.e. Mars). In order for this step of human colonisation to become a reality, engineers back on earth are assigned the highly challenging task in finding efficient and cost-effective ways to build structures that will be able to support life and scientific activity whilst resisting Martian/Lunar environmental threats such as micro-meteoroid impacts, solar and cosmic radiation, intense temperature loads, etc. Numerous studies are available in the literature proposing and engineering ways in fabricating habitats by either dwelling caves underneath the surface or via the concept of In-Site Resource Utilisation (ISRU) to use indigenous materials, readily available onsite to build such habitat structures (8-10). 
Additive manufacturing, also known as $3 D$ Printing, is a novel range of advanced manufacturing techniques, that in combination with the ISRU concept could serve as a feasible solution to this significant off-world engineering challenge. To date only a limited number of research studies have been performed under this topic and most of the proposed approaches are facing significant challenges prior to any potential adoption $(9,11-16)$.

In this paper a PBF process with a thermal energy source was investigated as to its potential as an off-world manufacturing solution to the aforementioned challenges. The PBF process was used to attempt to fuse together particulates of ceramic multicomponent materials that simulated Lunar and Martian regolith.

Although "regolith" is a terrestrial term, it is used to denote Lunar and Martian soil; soil is a pedogenic term used only in reference to Earth's geotechnical material (17) and refers to a complex layer of unconsolidated rock debris that have been derived by the fragmentation of the bedrock due to minor meteoritic impacts on the Lunar and Martian surfaces (18).

\section{2 - MATERIALS AND METHODS}

\section{1 - Materials}

The research presented, was carried out using commercially available simulants, developed in coordination with the Johnson Space Center at NASA and supplied by Orbital Technologies Corporation, Colorado, USA. The Lunar simulant JSC-1A has been characterized as a crushed basalt, rich in glass and oxidized forms of silicon, aluminum, iron, calcium and magnesium (19), with a composition matching actual lunar soil, but 
containing less material complexities due to it not having been exposed to "space weathering" conditions such as those explained in the introduction. (20).

The Martian simulant material JSC-Mars-1A consists mainly of palagonitic tephra (weathered volcanic ashes) and was mined on Earth in a cinder cone in Hawaii. The specific material was chosen due to the spectral similarities to the bright regions of Mars as measured by X-Ray Fluorescence (XRF) and Alpha Particle X-ray Spectrometer (APXS) analyses performed onboard the Viking landers, Mars and Spirit Rover. (21-23).

Although an accurate representation of the material gathered by Martian landers, it is important to note that the simulant material is not a de-facto standard (i.e. the whole of the Martian surface is not made of the same material) and therefore this work is specifically focusing on build material that is available at the various Martian lander sites. The following Table 1 consists of a representation of the chemistry present in both simulants.

\section{2 - Manufacturing Equipment}

Manufacturing experimentation was conducted using commercial AM equipment, a Realizer SLM100A Selective Laser Melting (SLM) machine (Realizer GmbH, Borchen, Germany). The SLM100A carries on board an Ytterbium fiber laser manufactured by IPG Photonics (IPG Photonics Corp., Oxford, USA) producing laser radiation of $1.06-1.09$ $\mu \mathrm{m}$ wavelength, with a standard TEMoo Gaussian profile beam, of $50 \mathrm{~W}$ maximum power output and a $30-300 \mu \mathrm{m}$ spot size. All manufactured samples were built on a mild steel substrate plate that was available with the machine together with applying constant heating at $200^{\circ} \mathrm{C}$. The following Table 2 states the process parameters used during the 
experimental procedure. An experimental study was followed in order for a suitable process parameter window to be identified that would allow the successful fabrication of multiple layered structures. The feedstock Martian material was screened in order to match the equipment's requirements, from a $d(0.5): 350 \mu \mathrm{m}$ that corresponds to the as received powder particle size, to a $\mathrm{d}(0.5): 70 \mu \mathrm{m}$, as measured through laser diffraction. A laser beam spot size of $\varnothing 80 \mu \mathrm{m}$ was used and a minimum layer thickness of $150 \mu \mathrm{m}$ was selected based on previous empirical data, in order to account for the poor packing density of the feedstock material due to its angular shape; as shown in the SEM images in Figure 2

\section{3 - Analytical Methods}

A Hitachi TM 3030 Scanning Electron Microscope (SEM) (Hitachi High-Technologies Europe $\mathrm{GmbH}$, Krefeld, Germany) was utilized for surface morphology, internal porosity and material microstructure analysis of the laser melted and raw material samples. XRF spectroscopy (Orbis PC Micro-XRF Elemental Analyzer, EDAX, Mahwah, USA) equipped with an X-ray source of monochromatic Rh Ka radiation (30 $\mu \mathrm{m}$ aperture, $30 \mathrm{kV}, 1000 \mu \mathrm{A})$ and a $25 \mu \mathrm{m}$ Al filter was used to determine the change in elemental composition of the materials after laser processing. All results reported are normalized to $100 \%$.

The manufactured samples were prepared for SEM via a standard metallography technique on a Buehler AutoMet 250 (Buehler Inc., USA). They were mounted in a Buehler EpoxyThin 2 clear epoxy resin and ground using a SiC paper from P320 to P4000 grit 
size. Following grinding, polishing was carried out using a polishing cloth and $1 \mu \mathrm{m}$ diamond paste. Water was used as a cooling and lubricating liquid during the sample preparation. Prior to SEM, the samples were sputter coated using a Gold/Palladium alloy on a 40 seconds exposure time at $20 \mathrm{~mA}$ charge.

In order to quantify the relative porosity of the fabricated samples and the feedstock material, SEM imaging of the cross-sectioned samples was used. The acquired images were processed and binarized using a threshold value as shown in Figure 1. The relative porosity was calculated as a ratio of the black to white pixels which corresponded with the fraction of the surface voids over the total surface (24).

To test the hardness of the manufactured samples the Vickers micro-indentation method was used in accordance with the ASTM C1327 standard and measured with a Struers Durascan 70 (EMCOtest, Kuchl, Austria). A Vickers diamond pyramid indenter was used with a $200 \mathrm{~g}$ load for a 15 second dwell time. Hardness values were measured from 12 different locations on the built samples in order to acquire a range of hardness values across the laser processed areas. A total of 6 samples from each regolith material were used.

Thermal analysis of the Lunar and Martian regolith simulants was conducted using Thermo-Gravimetric Analysis (TGA) in order to determine the presence of volatile compounds. TGA measurements were conducted with a TA Instruments Q5000-IR (TA Instruments, Inc., Elstree, UK), in an Argon inert gas environment, at a heating rate of 10 $\stackrel{\circ}{ } \mathrm{C} / \mathrm{min}$, from room temperature up to $1000 \stackrel{\circ}{\circ}$. 
The light absorbance characteristics of the regolith simulants were investigated in a wide wavelength range and also at the operating wavelength of the laser system used (1.07 $1.09 \mu \mathrm{m})$. Visible to near-IR (NIR) spectra were obtained using a Jenway $6105 \mathrm{UV} /$ Visible (Jenway Ltd., Felsted, UK) spectrophotometer and far IR spectra were obtained using a Shimadzu FTIR-8400S (Shimadzu, Kyoto, Japan) spectrophotometer. Measurements were taken at room temperature using powder samples screened through a laboratory sieve of $125 \mu \mathrm{m}$ apertures.

Finally, the change in crystallinity or the presence of amorphous content in the laser processed samples was determined through the use of X-Ray Diffraction (XRD). XRD patterns were obtained using a Bruker D2 Phaser X-ray diffractometer (Bruker AXS, Karlsruhe, Germany, 2000), fitted with a 1-dimensional Lynxeye detector and using Ni filtered Cu Ka radiation $(\lambda=1.542 \AA)$ run at $30 \mathrm{kV}$ and $10 \mathrm{~mA}$. Patterns were recorded from $15-100^{\circ} 2 \theta$, using a step size of 0.01 and an equivalent time per step of 5 seconds. All data was processed using Bruker's proprietary software, DIFFRAC.EVA 3.1 (Bruker AXS, Karlsruhe, Germany, 2000) and evaluated by comparison to the International Centre for Diffraction Data (ICDD) Powder Diffraction Files.

\section{3 - RESULTS AND DISCUSSION}

A previous experimental study, mainly focused on building structures out of lunar regolith simulant, gave a process parameters window and a laser energy density range of $0.9-1$ $\mathrm{J} / \mathrm{mm}^{2}$ where samples with no macroscopic defects were built (25). This paper covers a significantly extended and deepened study by exploring the additive manufacturing potential of ceramic multicomponent materials mimicking not only Lunar soil but also 
Martian soil. A combination of process parameters within the parameter limits (Table 2), revealed a range of energy densities between $2.5-4 \mathrm{~J} / \mathrm{mm}^{2}$ where sufficient fusion was evident between the particulates of the material. Laser energy less than $2.5 \mathrm{~J} / \mathrm{mm}^{2}$ was proven not to be adequate to achieve sufficient fusion between the feedstock material particles and further energy increase caused the material to evaporate, as witnessed during processing. However during laser scanning of the first few layers, the material evaporated even in the lowest attempted settings, because of the poor absorption of the laser beam; thus indicating that a larger layer thickness should be chosen.

Porosity analysis (Figure 1) of the fabricated samples from both materials revealed lowest values of $40 \%$ porous for the Lunar material ( $1.01 \mathrm{~J} / \mathrm{mm}^{2}$ energy density used) and $59 \%$ porous for the Martian material $\left(2.8 \mathrm{~J} / \mathrm{mm}^{2}\right.$ energy density used). In both materials the reduction of porosity was correlated to the increase of the given laser energy until a saturation point was reached.

\section{1 - Hardness Measurements}

The Lunar regolith samples exhibited a relatively high hardness of $660 \pm 8 \mathrm{HV}$, and even higher $710 \pm 30 \mathrm{HV}$ for the Martian samples. Both are comparable to that of soda lime glass, $545 \pm 20 \mathrm{HV}$ a typical hard and glassy ceramic material used in many engineering applications.

3.2 - Elemental Analysis 
The following Figure 3 consists of a representation of the element concentrations of the build material prior and post laser processing. Both materials exhibited a reduction in the element concentration which is due to the low melting and decomposition temperatures of the mineral compounds, thus resulting in evaporation; this result is in line with previously gathered and published data by the authors (25).

\section{3 - Optical Properties}

In powder bed fusion the laser beam partially penetrates the irradiated material through naturally occurring pores and/or the inter-granular gaps; a result of poor packing density of the angular particles of the simulants. Thus the laser interacts with the particles below the top powder layer, leading to particle re-arrangement and non-uniformity that changes the absorbance characteristics of the material (26). Absorbance is a dimensionless number defined as the ratio of the absorbed radiation to the incident radiation. Investigation into the optical characteristics of the regolith simulants was performed to identify and optimise processing parameters, such as the required energy density, for each material to be processed by the laser system. The greater the absorbance value of a material the less energy input is needed for it to be adequately fused and to avoid unwanted implications (i.e. vaporization). Figure 4 depicts the absorbance values of the regolith simulants throughout the visible to NIR spectrum.

Both feedstock powder materials have exhibited absorbance values of 0.9 for the Lunar and 0.6 for the Martian simulant, at the ytterbium fibre laser operating wavelength (1.06$1.09 \mu \mathrm{m})$. This result revealed that the specific type of laser used was suitable to be used as it is better absorbed by both materials and less energy density input will be required in order to achieve sufficient consolidation between the particles of the feedstock material. 
However a small and unquantified deviation is expected in the experimental results due to the presence of $\mathrm{CO}_{2}$ and water vapour in the laboratory ambient air that are known to absorb a portion of the NIR radiation. It is suggested that absorption characteristics will be improved when laser processing takes place in a vacuum or inert environment. An additional investigation for the purpose of employing an IR $\mathrm{CO}_{2}$ laser was conducted; however both materials exhibited a highly reflective behaviour when being irradiated with higher wavelengths (i.e. $10.6 \mu \mathrm{m}$ ); $\mathrm{CO}_{2}$ laser, as also shown in Figure 4.

A closer look at the wavelength range corresponding to visible light $(0.4-0.7 \mu \mathrm{m})$ showed relatively higher absorption values for both materials when compared to the NIR (1.07 $1.09 \mu \mathrm{m})$ and $\mathrm{IR}(10.57-10.63 \mu \mathrm{m})$ wavelength. These results suggested that an alternative energy solution to NIR laser may be possible which may aid any future application and development of the technology for off-world situations.

\section{4 - Thermal Analysis}

TGA of the lunar simulant did not reveal any significant mass losses suggesting that the material does not contain any volatile constituent (below $1000^{\circ} \mathrm{C}$ ). A small mass gain of $0.8 \%$ though was evident and it can be explained due to the oxidation reactions of Iron Oxide compounds that occur under laser processing conditions as previous research suggests (27). The minimum weight value of $99.96 \%$ at the temperature of $323 \stackrel{\circ}{\circ}$ suggests the complete evaporation of the moisture attached to the particles of the lunar simulant when exposed to atmosphere. Results on the Martian regolith simulant, revealed a more significant mass loss of $30.18 \%$ until the highest recorded temperature of $963 \stackrel{\circ}{\circ}$. The graph displayed a continuous trend of mass loss throughout the run but due to 
limitations of the equipment there was no data past that point. A further look at the mass loss profile revealed an initial volatile melt in the $120-325 \stackrel{\circ}{\mathrm{C}}$ range and past that point continuous melting and decomposition of the material. It has been suggested that the mass losses are dominated by the water content and potentially sulphur dioxide (21).

Finally, an overlay of the TGA curves of both materials is shown in Figure $\mathbf{5}$ and clearly shows the volatile behaviour of the Martian simulant as opposed to the Lunar, thus revealing the issues (poor sintering/melting behaviour) that came forward during the laser melting experiments where the material was evaporating throughout a large range of laser energy density inputs.

Overall results suggest that the Martian material is less stable in regards to thermal input when compared to the Lunar one, thus making it much more difficult to process since a significant portion will evaporate under any given thermal input.

\section{5 - X-Ray Diffraction}

Figure 6 depicts the X-Ray diffraction patterns acquired from both the un-processed (RAW MATERIAL) and the laser processed lunar regolith simulant (3D PRINTED) accordingly. No significant difference between the identified crystalline phases was shown, since phases of Forsterite-rich Olivine, IImenite and various Anorthite-rich Plagioclase minerals were present in both cases; before and after laser processing. However the wider and less intense peaks in the laser processed diffraction patterns suggested that there was an increase in amorphous content. The high amount of silicon oxide ( $50 \%)$ in the lunar regolith material can facilitate the formation of amorphous glass due to the high cooling rates achieved during processing, as discussed previously (11). 


\section{4 - CONCLUSIONS}

This study presented, an experimental feasibility investigation in additively manufacturing/3D printing physical assets, for off-world onsite manufacturing out of ceramic multicomponent materials via the use of thermal based powder bed fusion. The research was conducted with suitable simulants, mimicking the mineralogical properties of the indigenous materials found off-world (i.e. the Lunar and Martian surface).

A range of suitable energy density inputs was identified for each material used. An input of $0.9-1 \mathrm{~J} / \mathrm{mm}^{2}$ for the Lunar and $2.5-4 \mathrm{~J} / \mathrm{mm}^{2}$ for the Martian material could successfully fuse the simulant material into three dimensional built samples with no macroscopic defects. The optical and thermal properties of the feedstock materials were investigated, together with the mechanical properties and the difference in the element concentration of the 3D printed parts. The effect of change in crystallinity was also investigated for the Lunar material. Overall results suggest that the Lunar regolith is more appropriate for powder bed fusion additive manufacturing use than Martian regolith.

Future work in the specific area would include further process optimization towards improving built parts density and also a study into using alternative thermal power inputs.

\section{ACKNOWLEDGEMENTS}

The authors would like to thank Dr. Keith Yendall at the Loughborough Materials Characterization Center (LMCC) for his help using X-Ray Diffraction (XRD). 


\section{REFERENCES}

1. Devezas T, de Melo FCL, Gregori ML, Salgado MC V., Ribeiro JR, Devezas CBC. The struggle for space: Past and future of the space race. Technol Forecast Soc Change [Internet]. Elsevier Inc.; 2012 Jun [cited 2014 Jul 28];79(5):963-85. Available from: http://linkinghub.elsevier.com/retrieve/pii/S0040162511002848

2. Mueller GE. Man and the moon-The history of lunar exploration. Acta Astronaut. 1988;17(7):655-7.

3. Smith PH, Tamppari LK, Arvidson RE, Bass D, Blaney D, Boynton W V, et al. H2O at the Phoenix landing site. Science. 2009;325(5936):58-61.

4. Anderson RC, Beegle LW, Hurowitz J, Hanson C, Abbey W, Seybold C, et al. The Mars Science Laboratory scooping campaign at Rocknest. Icarus [Internet]. Elsevier Inc.; 2015;256:66-77. Available from: http://linkinghub.elsevier.com/retrieve/pii/S0019103515001347

5. Accomazzo A, Ferri P, Lodiot S, Pellon-Bailon J-L, Hubault A, Porta R, et al. Rosetta operations at the comet. Acta Astronaut [Internet]. Elsevier; 2015; Available from: http://linkinghub.elsevier.com/retrieve/pii/S0094576515002544

6. Hufenbach B, Reiter T, Sourgens E. ESA strategic planning for space exploration. Space Policy [Internet]. Elsevier Ltd; 2014;30(3):174-7. Available from: http://dx.doi.org/10.1016/j.spacepol.2014.07.009

7. Salotti JM, Heidmann R. Roadmap to a human Mars mission. Acta Astronaut [Internet]. Elsevier; 2014;104(2):558-64. Available from: http://dx.doi.org/10.1016/j.actaastro.2014.06.038

8. Khoshnevis B, Bodiford M. Lunar contour crafting-a novel technique for ISRUbased habitat development. 43rd AIAA Aerospace ... [Internet]. 2005 [cited 2014 Sep 4]. p. 1-12. Available from: http://arc.aiaa.org/doi/pdf/10.2514/6.2005-538

9. Corrias $\mathrm{G}$, Licheri R, Orrù R, Cao G. Self-propagating high-temperature reactions for the fabrication of Lunar and Martian physical assets. Acta Astronaut. 2012;70:69-76.

10. Faierson EJ, Logan K V, Stewart BK, Hunt MP. Demonstration of concept for fabrication of lunar physical assets utilizing lunar regolith simulant and a geothermite reaction. Acta Astronaut. 2010;67(1-2):38-45.

11. Balla VK, Roberson LB, OConnor GWO, Trigwell S, Bose S, Bandyopadhyay A. First Demonstration on Direct Laser Fabrication of Lunar Regolith Parts. Rapid Prototyp J. 2010;18(6):451-7.

12. Krauss H, Zaeh MF. Investigations on Manufacturability and Process Reliability of Selective Laser Melting. Phys Procedia [Internet]. Elsevier Srl; 2013 Jan [cited 2014 Aug 15];41:815-22. Available from: http://linkinghub.elsevier.com/retrieve/pii/S1875389213001673

13. Sen S, Ray CS, Reddy RG. Processing of lunar soil simulant for space exploration 
applications. Mater Sci Eng A. 2005;413-414(0):592-7.

14. Fateri M, Maziar K. On-site Additive Manufacturing by Selective Laser Melting of composite objects [Internet]. Concepts and Approaches for Mars Exploration. 2012 [cited 2014 Feb 12]. p. 842-5. Available from: http://www.lpi.usra.edu/meetings/marsconcepts2012/pdf/4368.pdf

15. Kading B, Straub J. Utilizing in-situ resources and 3D printing structures for a manned Mars mission. Acta Astronaut [Internet]. Elsevier; 2015;107:317-26. Available from: http://linkinghub.elsevier.com/retrieve/pii/S0094576514004901

16. Cesaretti G, Dini E, De Kestelier X, Colla V, Pambaguian L. Building components for an outpost on the Lunar soil by means of a novel 3D printing technology. Acta Astronaut [Internet]. Elsevier; 2014 Jan [cited 2014 Feb 6];93:430-50. Available from: http://linkinghub.elsevier.com/retrieve/pii/S0094576513002889

17. Ettouney MMM, Benaroya $\mathrm{H}$. Regolith mechanics, dynamics, and foundations. J Aerosp Eng [Internet]. 1992 [cited 2014 Aug 19];5(1559):214-29. Available from: http://ascelibrary.org/doi/abs/10.1061/(ASCE)0893-1321(1992)5:2(214)

18. Eckart P. The Lunar Base Handbook: An Introduction to Lunar Base Design (GNRL USE) [Internet]. McGraw-Hill; 2006. 864 p. Available from: http://books.google.co.uk/books?id=mp7dnQEACAAJ

19. Arslan $\mathrm{H}$, Sture $\mathrm{S}$, Batiste $\mathrm{S}$. Experimental simulation of tensile behavior of lunar soil simulant JSC-1. Mater Sci Eng A [Internet]. 2008 Apr [cited 2014 Jul 31];478(12):201-7. Available from: http://linkinghub.elsevier.com/retrieve/pii/S0921509307011203

20. Patrick EL, Mandt KE, Escobedo SM, Winters GS, Mitchell JN, Teolis BD. A qualitative study of the retention and release of volatile gases in JSC-1A lunar soil simulant at room temperature under ultrahigh vacuum (UHV) conditions. Icarus [Internet]. Elsevier Inc.; 2015; Available from: http://dx.doi.org/10.1016/j.icarus.2015.03.015

21. Allen CC, Morris R V., Karen MJ, Golden DC, Lindstrom MM, Lockwood JP. Martian Regolith Simulant JSC-Mars-1. Lunar and planetary science conference XXIX. 1998. p. 1690.

22. Allen CC, Jager KM, Morris R V., Lindstrom DJ, Lindstrom MM, Lockwood JP. Martian soil stimulant available for scientific, educational study. Eos, Transactions American Geophysical Union. 1998. p. 405-405.

23. Bonin B. Extra-terrestrial igneous granites and related rocks: A review of their occurrence and petrogenesis. Lithos [Internet]. Elsevier B.V.; 2012;153:3-24. Available from: http://dx.doi.org/10.1016/j.lithos.2012.04.007

24. Monroy K, Delgado J, Ciurana J. Study of the pore formation on CoCrMo alloys by selective laser melting manufacturing process. Procedia Eng [Internet]. Elsevier B.V.; 2013 Jan [cited 2014 Aug 17];63:361-9. Available from: http://linkinghub.elsevier.com/retrieve/pii/S1877705813014409

25. Goulas A, Friel RJ. 3d Printing with Moondust. Rapid Prototyp J [Internet]. 2016;22(5):IN PRESS. Available from: 
https://lupin.Iboro.ac.uk/viewobject.html?id=242638\&cid=1

26. Gaier JR, Ellis S, Hanks N. Thermal Optical Properties of Lunar Dust Simulants and Their Constituents. J Thermophys Heat Transf [Internet]. 2011 Oct [cited 2014 Mar 12];26(4):573-80. Available from: http://arc.aiaa.org/doi/abs/10.2514/1.T3838

27. Ray CS, Reis ST, Sen S, O'Dell JS. JSC-1A lunar soil simulant: Characterization, glass formation, and selected glass properties. Journal of Non-Crystalline Solids [Internet]. Elsevier B.V.; 2010 [cited 2014 Jan 28]. p. 2369-74. Available from: http://linkinghub.elsevier.com/retrieve/pii/S0022309310002395 


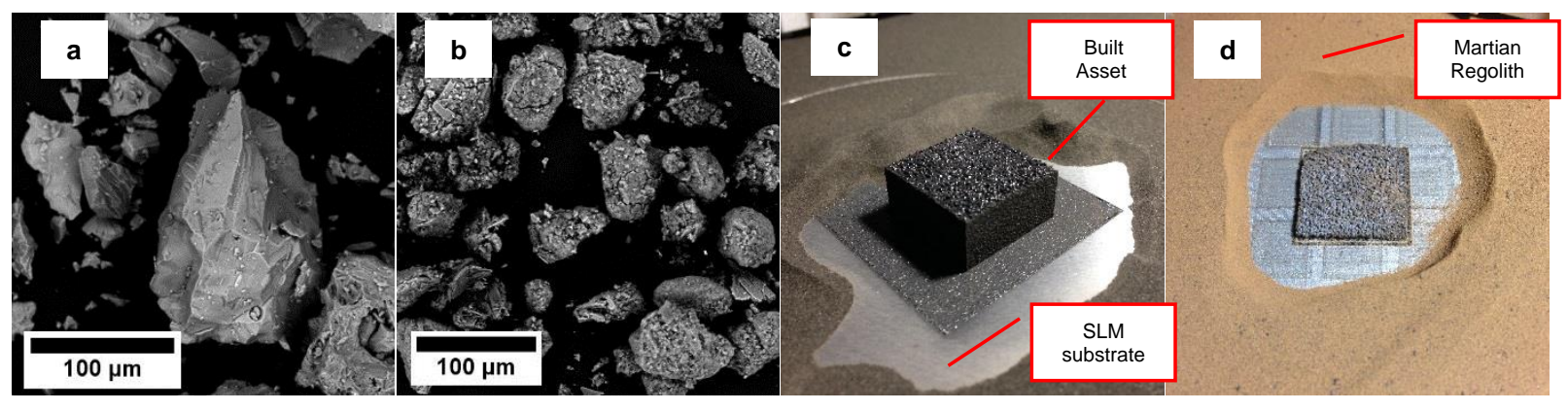

Figure 1 - SEM Micrograph of Lunar $(a, c)$ and Martian $(b, d)$ regolith simulant particles and additively manufactured samples. 


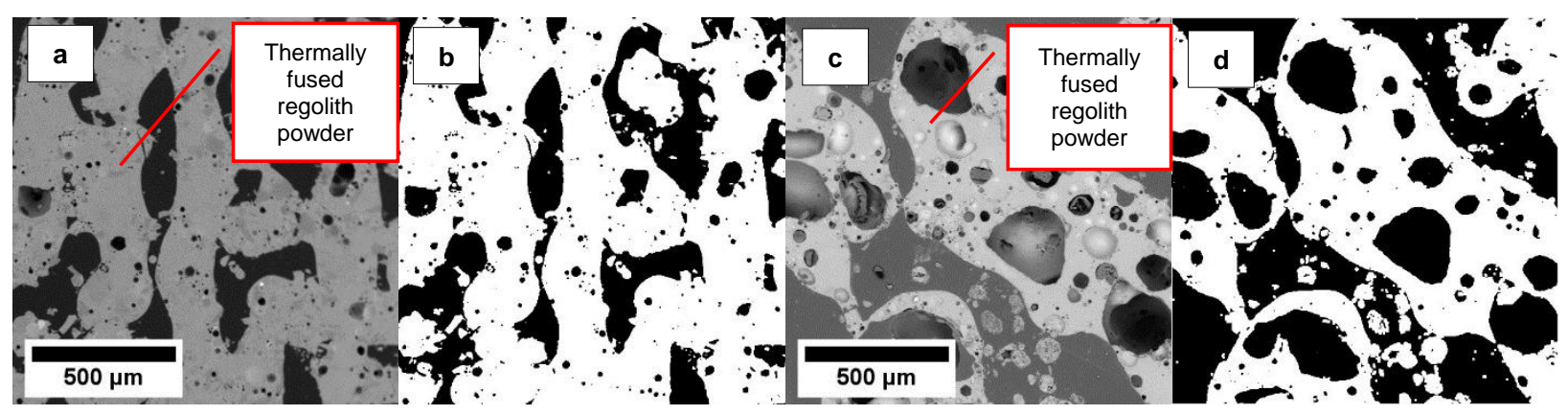

Figure 2 - Examples of binary processed SEM images of Lunar (a-b) and Martian (c-d) materials. 

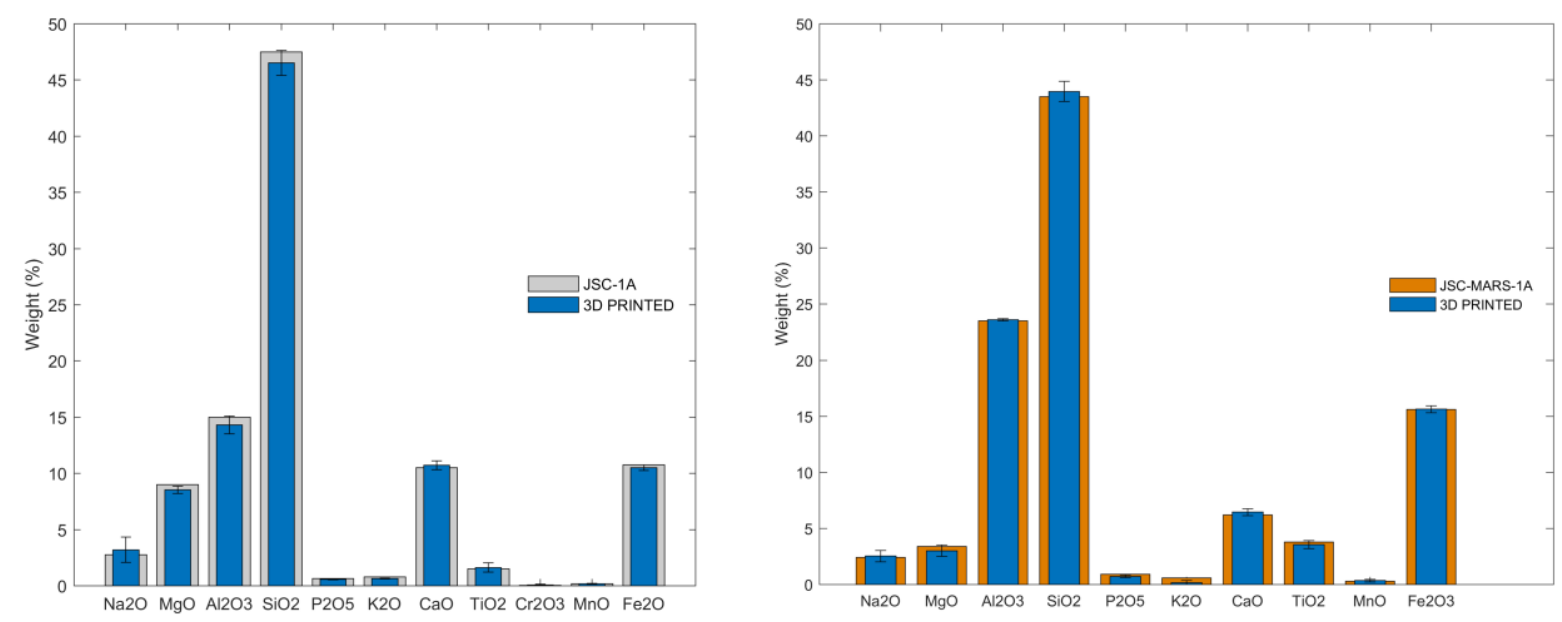

Figure 3 - Elemental concentrations (Wt.\%) between Additively Manufactured Lunar (left) and Martian (right) regolith samples and raw material powders acquired via X-Ray Fluorescence Spectroscopy (XRF). 

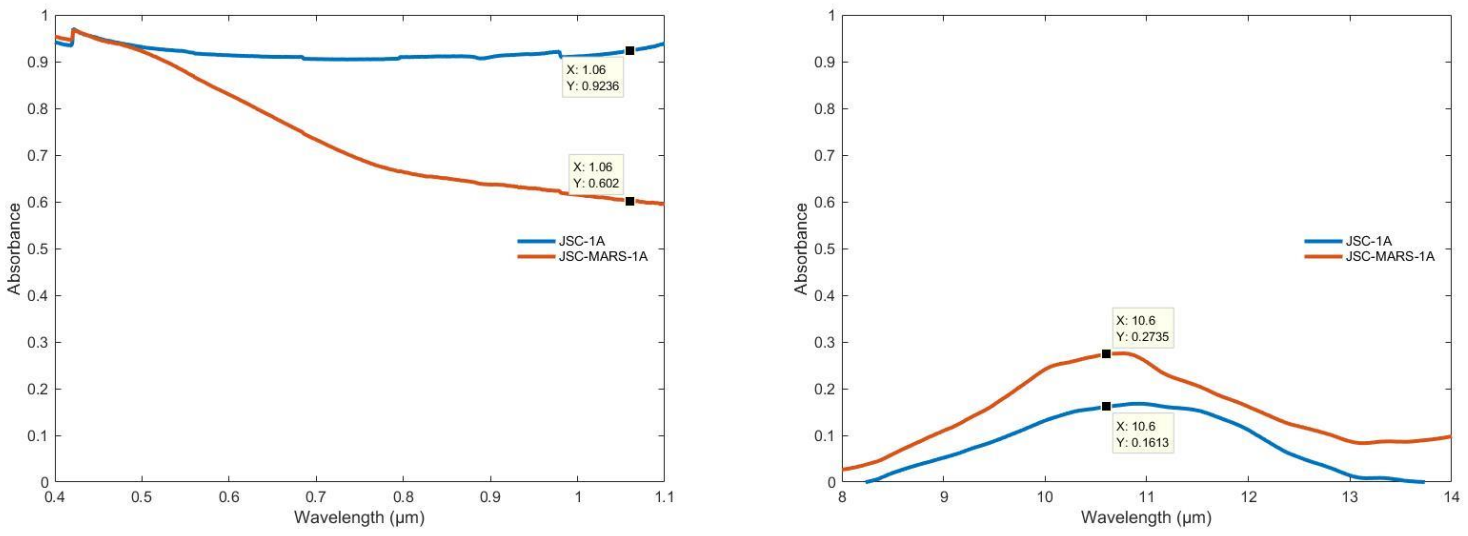

Figure 4-Absorbance of regolith simulants from the visible to the NIR spectrum (left) and IR (right) spectra. 


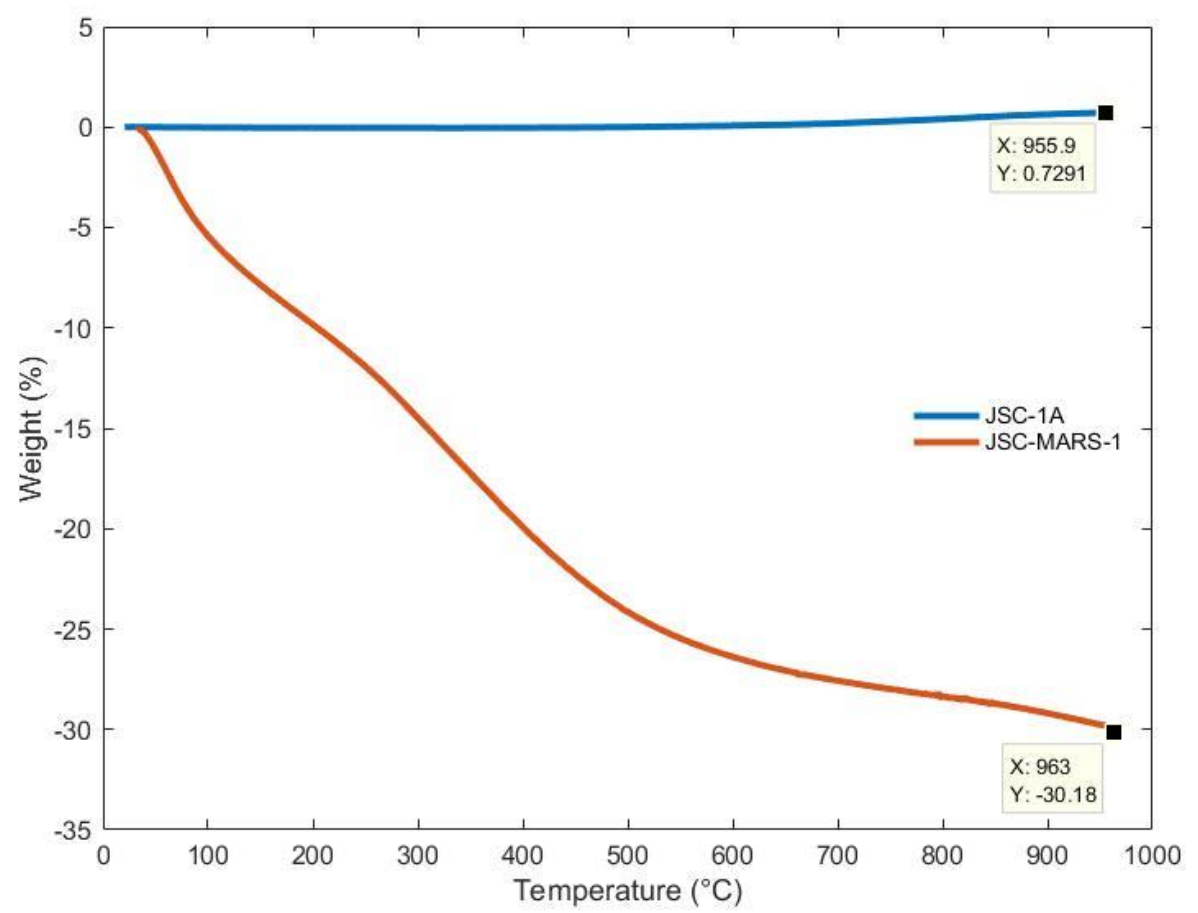

Figure 5-TGA curves overlay of Lunar and Martian Regolith Simulants. 


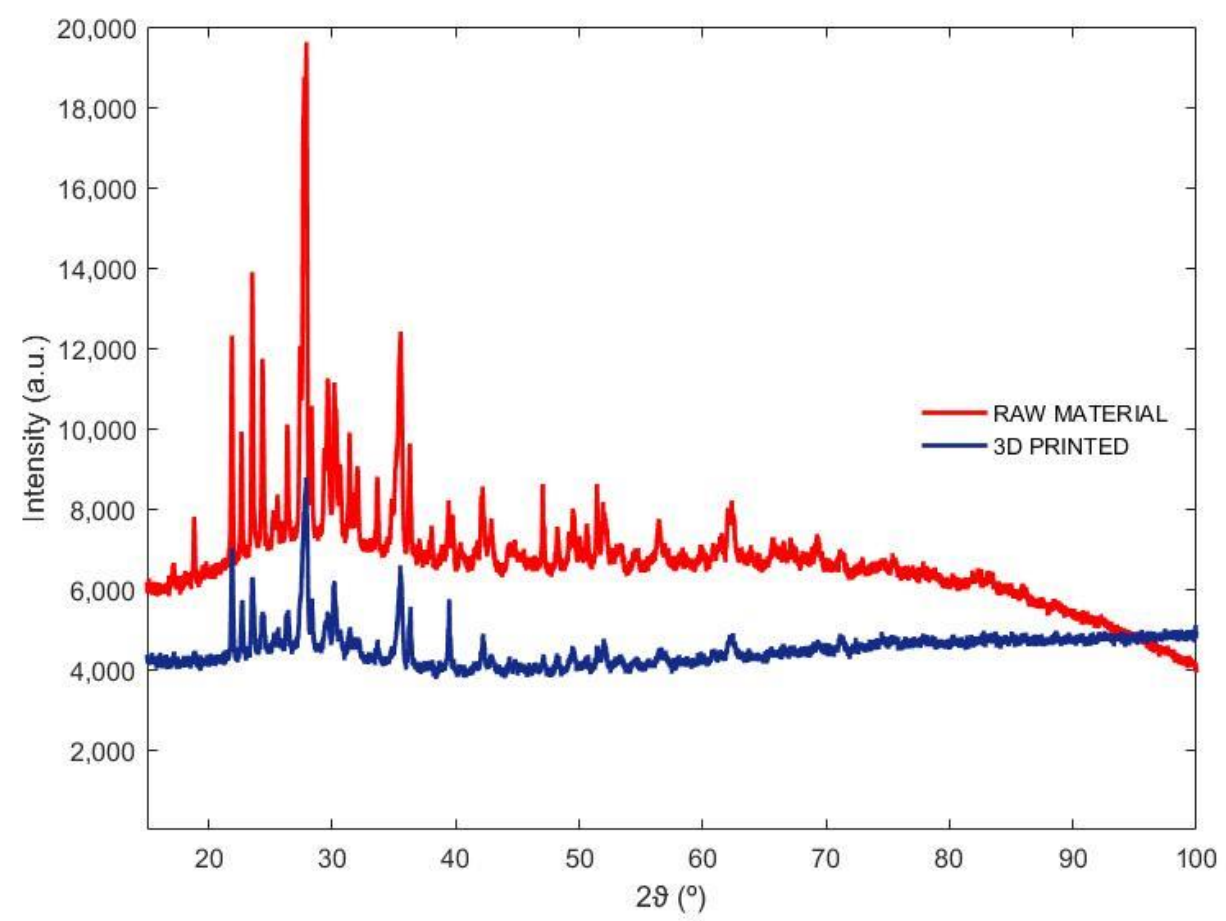

Figure 6 - X-Ray Diffraction patterns of un-processed (RAW MATERIAL) and laser processed (3D PRINTED) lunar regolith simulant. 
Table 1 - Composition (Wt.\%) of the major constituents in the JSC-1A Lunar Regolith

Simulant and JSC-MARS-1 Martian Regolith Simulant.

\begin{tabular}{lll}
\hline Chemical Compound & $\begin{array}{l}\text { Lunar Regolith Simulant } \\
\text { (Orbitec, 2005) }\end{array}$ & $\begin{array}{l}\text { Martian Regolith Simulant } \\
\text { (Orbitec, 2008) }\end{array}$ \\
\hline Silicon Dioxide $\left(\mathrm{SiO}_{2}\right)$ & $46-49$ & $34.5-44$ \\
Titanium Dioxide $\left(\mathrm{TiO}_{2}\right)$ & $1-2$ & $3-4$ \\
Aluminum Oxide $\left(\mathrm{Al}_{2} \mathrm{O}_{3}\right)$ & $14.5-15.5$ & $18.5-23.5$ \\
Ferric Oxide $\left(\mathrm{Fe} \mathrm{O}_{3}\right)$ & $3-4$ & $9-12$ \\
Iron Oxide $(\mathrm{FeO})$ & $7-7.5$ & $2.5-3.5$ \\
Magnesium Oxide $(\mathrm{MgO})$ & $8.5-9.5$ & $2.5-3.5$ \\
Calcium Oxide $(\mathrm{CaO})$ & $10-11$ & $5-6$ \\
Sodium Oxide $\left(\mathrm{Na}_{2} \mathrm{O}\right)$ & $2.5-3$ & $2-2.5$ \\
Potassium Oxide $\left(\mathrm{K}_{2} \mathrm{O}\right)$ & $0.75-0.85$ & $0.5-0.6$ \\
Manganese Oxide $\left(\mathrm{MnO}^{2}\right)$ & $0.15-0.20$ & $0.2-0.3$ \\
Chromium III Oxide $\left(\mathrm{Cr}_{2} \mathrm{O}_{3}\right)$ & $0.02-0.06$ & - \\
Diphosphorus Pentoxide $\left(\mathrm{P}_{2} \mathrm{O}_{5}\right)$ & $0.6-0.7$ & $0.7-0.9$ \\
\hline
\end{tabular}


Table 2 - Process parameters used during the experimental procedure.

\begin{tabular}{ll}
\hline Parameters & Value \\
\hline Laser & Near-IR $(\mathrm{NIR})$ Ytterbium Fibre Laser \\
Power $(\mathrm{W})$ & $5-50$ \\
Wavelength $(\mu \mathrm{m})$ & $1.06-1.09$ \\
Diameter of Laser Spot $(\mu \mathrm{m})$ & 80 \\
Point Distance $(\mu \mathrm{m})$ & $30-1000$ \\
Hatching Space $(\mu \mathrm{m})-($ Overlap \%) & $52-80(35 \%-0 \%)$ \\
Exposure Time $(\mu \mathrm{sec})$ & $100-1000$ \\
Thickness of Powder Layer $(\mu \mathrm{m})$ & $150-300$ \\
Velocity $(\mathrm{mm} / \mathrm{s})$ & Point Distance/Exposure Time \\
Environment & Argon Atmosphere \\
Temperature of substrate $\left({ }^{\circ} \mathrm{C}\right)$ & 200 \\
Substrate material & Mild steel \\
\hline
\end{tabular}

